\title{
How do e-book readers enhance learning opportunities for distance work-based learners?
}

\author{
Ming Nie ${ }^{\mathrm{a} *}$, Alejandro Armellini ${ }^{\mathrm{a}}$, Gabi Witthaus ${ }^{\mathrm{a}}$ and Kelly Barklamb ${ }^{\mathrm{b}}$ \\ ${ }^{a}$ Beyond Distance Research Alliance, University of Leicester, Leicester, UK; ${ }^{b}$ Zeal Solutions \\ Ltd, London, UK
}

(Received 17 September 2010; final version received 9 December 2010)

\begin{abstract}
We report on the incorporation of e-book readers into the delivery of two distancetaught master's programmes in Occupational Psychology (OP) and one in Education at the University of Leicester, UK. The programmes attract work-based practitioners in OP and Teaching English to Speakers of Other Languages, respectively. Challenges in curriculum delivery included the need for more flexibility in the curricula, better access to essential readings and maximising the benefit of learners' limited study time. As part of a suite of pilot changes to curriculum design and delivery, 28 Sony PRS-505 ${ }^{\mathrm{TM}}$ e-book readers were preloaded with course materials and sent out to students. The evidence suggests that the students' learning experiences improved as a result of four key benefits afforded by the e-book readers: enhanced flexibility in curriculum delivery to accommodate the mobile lifestyle of our learners, improved efficiency in the use of study time, especially short breaks during the working day, new strategies for reading course materials and cost. We discuss the opportunities and limitations associated with the e-book readers used and the challenges encountered in the study.
\end{abstract}

Keywords: e-book reader; distance learning; work-based learning; m-learning; flexibility; innovation

\section{Introduction}

This paper reports a study of the incorporation of e-book readers into the curriculum delivery of two distance-taught master's programmes in Occupational Psychology (OP) and one in Education at the University of Leicester, UK. We discuss how e-book readers were used on work-based distance learning courses at the University of Leicester to address some of the challenges faced by learners on the three programmes.

An e-book reader is an electronic device designed primarily for reading digital files such as electronic books (e-books). It is smaller, lighter and cheaper than a small laptop computer or netbook and uses black-and-white e-ink technology, as opposed to an LCD or backlit screen. Storage capacity and functionalities such as wireless connectivity and annotation features vary between models. The model used in this research was the Sony PRS-505 ${ }^{\mathrm{TM}}$. Other examples of e-book readers include the Amazon Kindle ${ }^{\mathrm{TM}}$ and the Sony Pocket ${ }^{\mathrm{TM}}$.

*Corresponding author. Email: mn79@leicester.ac.uk 
In the light of earlier research, we evaluate the potential of e-book readers for work-based distance learners. We show how the e-book readers were integrated into the three curricula and describe the process that led to the production and loading of materials. We present our research methods and discuss our key findings in terms of the potential and limitations of e-book readers as a learning technology for delivering content for work-based distance learning programmes at master's level.

\section{Background}

\section{Mobile technology for work-based learning}

Work-based learning plays an important role in meeting the demand for increasing the employability of university graduates (Clamp and Warr 2002; Hills et al. 2003). Most higher education institutions already have work-based learners as a vital segment of their target audience in their teaching and learning agendas. Work-based learning also acts as a driver for innovation in the higher education system (Nixon et al. 2006). Evidence suggests that work-based learning can be more resource-intensive than other modes of learning (Nixon et al. 2006). To provide cost-effective work-based learning solutions, higher education institutions need a more flexible approach (Gallacher and Reeve 2002) and more innovation in using new technologies in delivery (Brennan 2005). This will enable students to have greater control over when and where their learning takes place and build their learning around other work and life commitments (Fagerberg and Rekkedal 2004).

Work-based learning has been defined as learning at higher education level carried out for work, through work and at work (Gray 2001). In this article, we use the term work-based learners to refer to students registered on formal higher education programmes of study who meet one or more of the following criteria:

- The programme of study, which they follow while in employment, is directly related to and with immediate application to their jobs (Andresen, Boud, and Cohen 1999).

- They do some or all of their learning while performing work-related activities, including travel.

- They do some or all of their learning at the workplace.

Work-based learners typically lead busy and demanding lives. They travel a lot and struggle to find enough time for studying. Their mobile and time-poor lifestyles lead them to seek more flexibility and freedom to choose where and when to study. They require solutions that support learning on the move. The innovative applications of mobile technologies, including the use of pocket PCs, personal digital assistants and mobile phones have proved effective in extending and increasing the flexibility of learning programmes and the mobility of distance learners (Rekkedal et al. 2005).

Access to e-libraries and other essential digital learning resources by learners in work placements is another challenge faced by work-based learners (Walton, Childs, and Blenkinsopp 2005). Some higher education institutions are experimenting with ways to use the affordances of mobile technologies to give these students the same level and quality of access as a computer on the university campus. At Athabasca University, for example, a digital reading room was established for the delivery of course materials to personal digital assistants, mobile phones and other mobile devices 
to increase the flexibility of accessing learning resources for mobile distance learners (McGreal et al. 2005).

The potential for e-books to support distance learning has also been investigated. Shiratuddin et al. (2003) found that the use of e-books could improve access to teaching and learning materials for distance learners. A more recent study investigating the usability and usefulness of e-books in an m-learning environment indicated the following advantages for student learning: increasing access (e.g. more readings, multimedia and portable resources), enabling remote access, and optimising reading time (Lam, Lam, and McNaught 2010). Whalley (2010) argues that there will be an increasing use of e-books by students on and off campus, given the financial pressures faced by all UK higher education institutions and the tuition fees paid by students. Mobile devices such as e-book readers might offer affordable solutions for course content delivery.

This article reports on one of the possible ways in which e-book readers can be integrated into curriculum delivery at master's level.

\section{Context for the study}

The University of Leicester is a sector leader in postgraduate distance education. Since the early 1990s, over 18,000 students have earned degrees by studying at a distance. The university currently has over 7000 students on 40 distance learning programmes offered by 13 departments. Over $50 \%$ of the distance students are outside the European Union, with large numbers in Africa, the Caribbean and the United Arab Emirates. The vast majority of distance students are enrolled on work-based master's programmes related to their professional lives. It is the university's mission to continue investing in and expanding the delivery of its work-based distance learning programmes and to enhance the experience of these learners through learning technologies.

Print is still the main delivery technology in most of Leicester's distance learning programmes. However, an increasing number of departments have opted for appropriate blends of online and print delivery. Six programmes are currently delivered solely or primarily online. This figure is likely to increase in the next 12 months.

Two master's programmes in OP and one in Applied Linguistics and Teaching English to Speakers of Other Languages (TESOL) were targeted for specific innovations. Almost all students on the three programmes are in employment. If successful, the innovations would be transferred to other programmes.

The School of Education at the University of Leicester has been delivering a master's programme in Applied Linguistics and TESOL by distance learning since 1995. The programme is aimed at graduate teachers with at least two years of Englishlanguage Teaching experience, who want to further their academic and professional development. Due to the nature of their work, most of these students are highly mobile, as they tend to travel internationally. The programme attracts about 90 parttime students per year, and can be completed within 2.5-5 years. It involves three 30credit modules, two option modules (30 credits in total) and a 60-credit dissertation. In September 2008, the Education team began to transfer the delivery of course materials to the university's Blackboard virtual learning environment (VLE) and gradually stopped sending printed materials to students.

The School of Psychology at the University of Leicester has been delivering two distance programmes since 2000: the MSc in Occupational Psychology and the 
Diploma/MSc in the Psychology of Work. Between them, these programmes attract about 50 part-time students per year, and can be completed over two years. Each programme involves six 20-credit modules and a 60-credit dissertation. In 2006, the OP team began to use the university's Blackboard VLE beyond a document repository to enhance the delivery of these programmes. Online activities and tutor-moderated discussion forums provided guidance on module content and assignments and support to learners at all stages of their dissertations. Course materials began to have their webbased versions and active links to course readings. Blackboard became the central hub for all student resources. Since 2007, students have submitted their assignments and dissertations through Blackboard's online submission system and marking by tutors is now fully electronic. The OP team started enriching the students' learning experience with additional interactive and portable online course materials in 2009.

A two-year Joint Information Systems Committee-funded (http://www.jisc.ac.uk) research project called DUCKLING (Delivering University Curricula: Knowledge, Learning and INnovation Gains; http://www.le.ac.uk/duckling) enabled both course teams to address curriculum delivery challenges through the appropriate incorporation of four technologies into learning design: podcasting, Second Life, Wimba ${ }^{\mathrm{TM}}$ Voice Boards and e-book readers. We have previously reported on the successful incorporation of podcasting for work-based learners in OP (Nie et al. 2010), focusing on challenges in the areas of learner isolation and mobility.

The primary purpose of the incorporation of e-book readers into the three programmes was to investigate whether these devices could enhance flexibility in curriculum delivery to better accommodate the needs and demands of highly mobile work-based learners. For example, could a stand-alone e-book reader, pre-loaded with course materials, help students to maximise their limited study time by increasing their access to the essential readings?

In the context of the above challenges and opportunities, our central research question was: how does the incorporation of the e-book reader into curriculum delivery affect the experiences of the work-based distance learners on these three master's programmes? The research was led by the Beyond Distance Research Alliance, an independent research, development and learning innovation unit at the University of Leicester.

\section{The pilot}

Between October 2009 and March 2010, 28 Sony e-book readers were sent out to 17 Education students and 11 OP students for trial. Twenty-seven of these e-book readers were Sony PRS-505 ${ }^{\mathrm{TM}_{\mathrm{S}}}$. As this model was discontinued in 2010, one of the Education students was given a Sony PRS-300 ${ }^{\mathrm{TM}}$, the replacement model for the PRS-505. Both models are similar in size, weight, features and price.

All 28 e-book readers were pre-loaded with course materials produced by the two course teams. The e-book readers given to $11 \mathrm{OP}$ students were pre-loaded with materials from three modules. Materials from the remaining modules were subsequently made available via the VLE for the students to download and transfer onto their e-book readers themselves, for which specific guidance was given. The e-book readers given to 17 Education students were pre-loaded with materials from one module. All materials were pre-loaded in ePub format. These materials were the same as those available, in multiple formats, via the VLE. The Education students also received a Sociolinguistics textbook on their e-book readers, for which copyright clearance had 
Table 1. Making course materials available on the e-book readers.

\begin{tabular}{|c|c|}
\hline Step & Description \\
\hline 1: Preparation & The course teams updated and proofread all materials. \\
\hline 2: Conversion & $\begin{array}{l}\text { A DUCKLING project learning technologist converted the source } \\
\text { materials into ePub format. The formatting was supported by } \\
\text { Calibre software (http://calibre-ebook.com/), a free, cross-platform } \\
\text { e-book reader management system. See how to turn a Word } \\
\text { document into ePub format in Figure } 1 \text {. }\end{array}$ \\
\hline 3: Pre-loading & $\begin{array}{l}\text { The re-formatted course materials (in ePub format) - and in the case } \\
\text { of the Education students, the socio-linguistics textbook - were } \\
\text { copied onto the e-book readers. }\end{array}$ \\
\hline 4: Delivery & The e-book readers were delivered to students. \\
\hline $\begin{array}{l}\text { 5: Updates in ePub } \\
\text { format via VLE }\end{array}$ & $\begin{array}{l}\text { Updated versions of the materials and new resources were uploaded to } \\
\text { Blackboard in ePub format for students to add to their e-book } \\
\text { readers. These files were also available in Word or PDF formats for } \\
\text { standard access. }\end{array}$ \\
\hline 6: Guidance & $\begin{array}{l}\text { The DUCKLING project team produced guidance documentation for } \\
\text { students to follow and instructions on how to add new materials } \\
\text { onto the devices, including journal articles from the digital library. }\end{array}$ \\
\hline
\end{tabular}

been obtained. The participating students were not required to return the e-book readers to the institution.

The steps presented in Table 1 were involved in preparing and sending out the e-book readers, and supporting students in the pilot.

The six-step process described in Table 1 was fully piloted as part of the DUCKLING project. The guidance document for conversion of files into ePub format is now available as an open educational resource (http://tinyurl.com/37sdzef) for other practitioners to use.

\section{Research methodology}

\section{Research questions}

The central research question aimed to establish the impact of the incorporation of ebook readers on work-based learners' experiences: how does the incorporation of the e-book reader into curriculum delivery affect the experiences of the work-based distance learners on these three master's programmes? It was approached through three sub-questions:

(1) What does the e-book reader offer in terms of flexibility and opportunities for mobility when work-based learners need access to course materials?

(2) What impact does the e-book reader have on how students study?

(3) What are the cost implications of the incorporation of e-book readers into the delivery of these distance programmes?

The questions were agreed on the basis of the challenges faced by the course teams, our collective interest in learning technology research and the institutional drive for learning innovation established in Leicester's Learning Innovation Strategy, approved by the University Senate in 2009. 


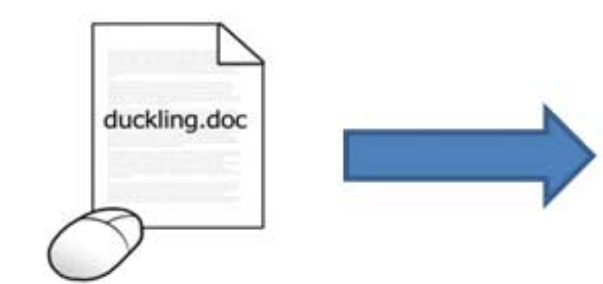

DUCKLING.doc

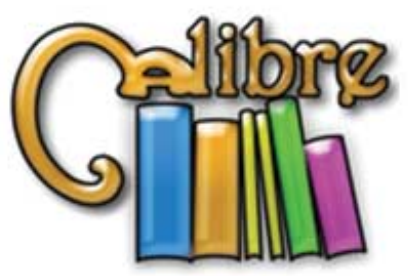

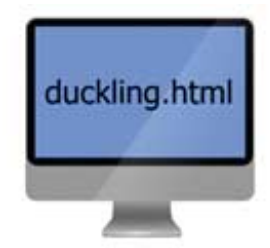

DUCKLING.html

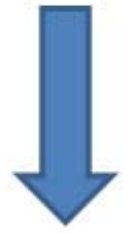

\section{ebook management}
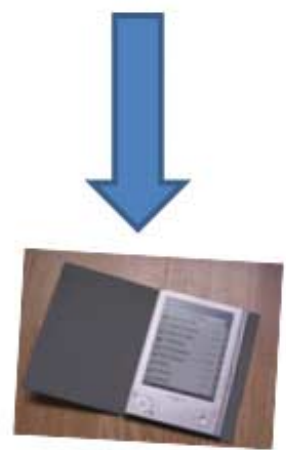

\section{DUCKLING. epub}

\section{Action research}

The research was conducted using an action research methodology that involved the "action-reflection" cycle (McNiff and Whitehead 2006, 9). As part of the DUCKLING project, the action-reflection cycle started before the incorporation of the four technologies into curriculum delivery. Through surveys and interviews, staff and students of both disciplines were consulted from the very start of the project on the challenges faced. Their views were analysed and results were fed back to the two teams to inform course redesign. As the new technologies (including the e-book readers) were incorporated into the redesign, feedback from students and staff was regularly gathered and analysed. Evidence was again fed back to the course teams to inform the next set of design changes. 
Table 2. Summary of the survey questions.

\begin{tabular}{ll}
\hline Category & Survey questions \\
\hline Usage & Where, how often and for how long (each time) did you use the course \\
materials on the e-book reader? & What other documents (in addition to the pre-loaded course materials) did you \\
& use on the e-book reader? \\
Usability & To what extent did you find the course materials on the e-book reader easy to \\
& read? \\
& How has the e-book reader changed the way you study? \\
& Rank and justify your preferences for reading the course materials, given the \\
& choices of having them in print, on the e-book reader or on Blackboard. \\
& How easy it is to transfer documents onto the e-book reader? \\
Usefulness & How helpful did you find the e-book reader in your studies? \\
& To what extent were you satisfied with the e-book reader? \\
& What functions were you satisfied and not satisfied with?
\end{tabular}

\section{The survey}

To understand the impact of the e-book readers on learners' experiences, data were first captured through a Blackboard survey. The e-book reader survey was administered online to capture usage, usability and usefulness of the e-book reader. The full list of questions used in the survey is shown in Appendix 1. A summary of the questions included in the survey, grouped by theme, is given in Table 2 . The survey was completed by all 28 students who had received the e-book readers, 17 from Education and 11 from OP.

The 17 Education students are all language teachers who teach English to speakers of other languages in a wide range of contexts in different countries around the world. The 11 OP students hold a variety of posts, such as retail managers, human resource officers, recruitment managers, personal coaches and freelance consultants. Table 3 summarises the number and gender distribution of the students who participated in the e-book reader research.

Quantitative data collected from the survey were transferred into Excel spreadsheets and descriptive statistics were applied to closed questions. Qualitative data gathered from the survey were coded using data-driven (inductive) coding (Boyatzis 1998) and analysed using thematic analysis (Boyatzis 1998; Joffe and Yardley 2004) to identify categories and combine categories into themes. The themes are reported in the Results section.

\section{Cognitive mapping}

To further understand the students' experiences with their e-book readers, cognitive mapping interviews (Bryson et al. 2004) were conducted with nine Education students and three OP students after the survey.

Cognitive mapping is a research method developed on the basis of Kelly's (1955) theory of personal constructs.

People make sense of their lives and situations by constructing, elaborating, revisiting and re-revising a system of interconnected concepts (more formally called 'constructs'). (Bryson et al. 2004, 21) 
Table 3. Respondents' profile.

\begin{tabular}{|c|c|c|c|c|c|c|c|}
\hline \multirow[b]{2}{*}{ Instrument } & \multicolumn{2}{|c|}{ Education students } & \multicolumn{2}{|c|}{ OP students } & \multicolumn{2}{|c|}{ Total } & \multirow[b]{2}{*}{ Total } \\
\hline & Male & Female & Male & Female & Male & Female & \\
\hline Survey & 9 & 8 & 2 & 9 & 11 & 17 & 28 \\
\hline Interview & 6 & 3 & 1 & 2 & 7 & 5 & 12 \\
\hline
\end{tabular}

This method has been used in studies in Psychology (Curseu, Schalk, and Schruijer 2010), Environment and Planning (van Kouwen et al. 2009), Management and Organisation (Harris and Woolley 2009), and strategy for adopting e-learning (Russell 2009).

In this study, the cognitive mapping process involved four steps: conducting the interview, creating a causal map, validation and analysis. The interviews were conducted via the telephone, as the students who participated in the study were all distance learners, and were digitally recorded. The interviews focused on two questions: what do students use their e-book reader for, and how do they use the device?

The second step was to develop a causal map from each interview. The causal map was used to capture each student's views, perceptions and experience of using the e-book reader. A causal map is

A word-and-arrow diagram in which ideas and actions are causally linked with one another through the use of arrows. The arrows indicate how one idea or action leads to another. (Bryson et al. 2004, 4)

Twelve causal maps (one per interview) were created using the Decision Explorer software (http://www.banxia.com/demain.html).

Figure 2 illustrates a fragment of a causal map created from an interview with an Education student regarding his use of the e-book reader. The links from Concept 3 to Concept 4, and from Concept 4 to Concept 2 are interpreted as "The module material is put in short sections", so "I can just read the material a little bit from the e-book reader, put it down, and pick it up and resume later", and for that reason "I've been using the e-book reader mainly at work when I've got a spare 15-20 minutes".

The third step is validation. In cognitive mapping, the causal map needs to be presented to the interviewee to ensure that the map is a true representation of his or her views and perceptions. As all participating students were distance learners, the validation was conducted electronically. Each student was sent a causal map developed from his or her interview, plus a letter explaining how the map was developed, how to interpret the concepts and arrows, and guidance on how to provide feedback to the researcher.

Once all causal maps had been validated by the interviewees, the analysis began. The Domain and Central analyses provided by Decision Explorer were applied to the 12 students' causal maps. In cognitive mapping, the Domain analysis calculates 'the total number of in arrows and out arrows from each node" (Bryson et al. 2004, 324). The result of the Domain analysis indicates the richness of meaning of each node. A node with the highest score indicates that it is the "nub of the issue" (Bryson et al. 2004, 324) of that map. The Central analysis calculates the centrality of a node within the map. A higher Central analysis score implies that the node is of structural significance 


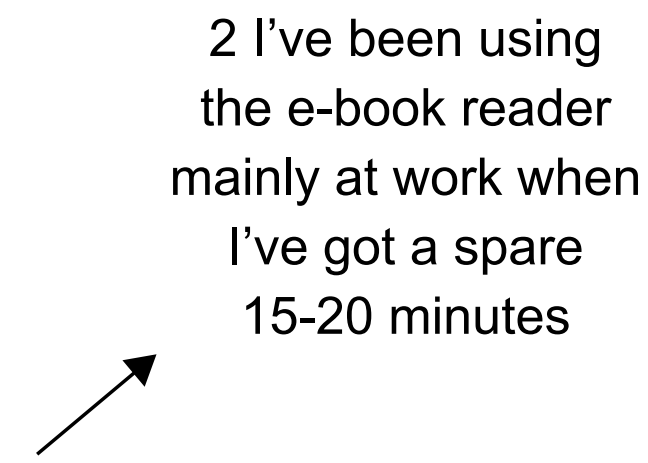

4 I can just read the material a little bit from the e-reader and put it down, pick it up and resume later

\section{The module material is put in short sections}

Figure 2. A fragment of a causal map.

to the map. Both Domain and Central analyses are used to detect the most important or "busiest" concepts. These concepts were compared and contrasted with the themes that emerged from the e-book reader survey.

\section{Results}

The e-book reader, as used in the context of this research, improved the experience of work-based distance learners in a number of ways. The findings also highlighted the current limitations of the technology used in the study. These findings are presented under four themes, mapped against the initial challenges that the course team faced.

\section{Flexibility to support the mobile lifestyles of learners}

Students highly valued the portability and flexibility that the e-book reader offers. They used their e-book readers in various ways and in different locations. Table 4 shows that 16 students from both disciplines used it in public places (such as a café) and 18 of them did so on the move (e.g. on a train, bus or aeroplane). 
Table 4. Where do students use their e-book readers?

\begin{tabular}{lccr}
\hline Location/place & Education students & OP students & Total \\
\hline At home & 9 & 8 & 17 \\
In the office & 6 & 3 & 9 \\
At public places (e.g. library, café) & 10 & 6 & 16 \\
On the move (e.g. train, bus, plane) & 11 & 7 & 18 \\
\hline
\end{tabular}

Students from both disciplines emphasised the benefit in terms of flexibility in response to the open questions in the survey:

The e-book reader is a lot more flexible in terms of where you study. I don't feel like I am confined to my desk. (Psy7)

The e-reader has increased my ability to study in more places without needing to carry around a bulky folder. (Edu4)

For the same reasons, students found it easy to use their e-book readers in public places and on the move, as one of the students expressed in the survey:

I loved the small size/weight and thought it would be practical to carry when I'm travelling by plane, car, etc., allowing me to study without transporting a lot of heavy books. I'm a bike commuter as well, so it would also be practical for daily trips to work, the library, or the beach or park, where I like to do a lot of my reading. (Edu3)

The readability of the e-book reader under different conditions makes it suitable for outdoor use. One student in Malta stated in the interview:

Malta is very sunny. There is an issue with the readability in the sun. The visibility of a laptop is a problem when you use it outdoors. The e-book reader can be so readable in the sun. From this point of view, the e-book reader is excellent. It's just like reading a paper. I take my e-book reader when I know that I'll have a bit of time on the boat. The e-book reader has made things much easier for me. (Psy3)

Many students felt that their reading experience from an e-book reader is similar to reading from a book. For students who do not enjoy reading from a computer screen, an e-book reader can be a welcome alternative, as one student stated in the survey:

I find it very difficult to read for long periods on my computer due to the eye strain, and have always relied on printing out long chapters in order to read more comfortably. With the e-book reader I can avoid all of that and read anytime and anywhere I like. (Edu10)

Accessing course materials from a single device without an Internet connection is considered another advantage by the students, as one pointed out in the survey:

I no longer worry about carrying so many papers in my bag or having an internet connection to access the modules material. I believe that it made my life easier. (Psy8)

Long battery life, capacity to accommodate many readings and a user-friendly interface were also considered key advantages. 
These findings suggest that the functionalities and portability of the e-book reader made the curricula more flexible, which catered for the mobility challenge faced by work-based distance learners. The device has made essential readings more accessible to students and their reading experience enjoyable.

\section{Study time}

The portability of the e-book reader and its many functionalities made it easier for students to take all course materials with them anywhere and read whenever they had a gap in their diaries. Many students pointed this out in the survey:

It's helpful from a practical point of view. The nature of distance learning means you have to squeeze in study whenever you have time. Having textbooks and journal articles stored together so conveniently is much better than reams of paper on a packed commuter train in Osaka. (Edu4)

I am using the e-reader to access the unit materials every day. This has increased the amount of course materials I have gotten through (I have finished reading through the Part A on Sociolinguistics). Before this, I had been allocating weekends to spend on one or two units, and I would only study through the week if I had a few hours to spare. (Edu5)

I find that the reader has become an integral part of my day in particular situations. I have a load of eight hours a week of CALL (Computer Assisted Language Learning) classes here, during which there is pretty much nothing to do. But since I've received the reader, after I open the lab I sit and start reading the material I've loaded and take notes on what interests me. The reader, then, has given me more study time during the day. It's nice to have the corpus of material I am working on loaded onto a single device. There's something nice about being able to look at all the documents I'm interested in, and get a kind of "big picture" from doing this. I've also gotten into the habit of carrying my reader with me everywhere, and if I'm in a situation where I'm waiting for 20 minutes I will automatically open the reader. How I kill time has been transformed by this device, as previously I would have just spent the 20 minutes playing games on my iPhone! (Edu6)

The Bookmark and Continue reading functions make the e-book reader extremely easy for students to turn off and restart where they left off. These functions increased the likelihood that students would use their e-book readers during their breaks (even short breaks) and on the move.

The analysis of students' cognitive maps revealed the same finding. A causal map developed from an interview with an Education student (Figure 3) shows how the device enabled him to make more effective use of his time. The e-book reader's functions and the opportunity to have all the course materials on this stand-alone device made it very convenient for carrying around and reading a few pages whenever he had a gap. As a result of this, this student took the device with him wherever he went. The device enabled him to do more readings while on the move.

These findings suggest that the e-book reader was a welcome addition to the lifestyles of work-based distance learners. The device helped them to make better use of 'dead time' and enabled them to fill gaps in a purposeful way.

\section{Learner study strategies}

Some students reported that their study strategies changed as a result of having the e-book reader. Table 5 shows that 11 students from both disciplines reported that the e-book reader changed the way they study. 


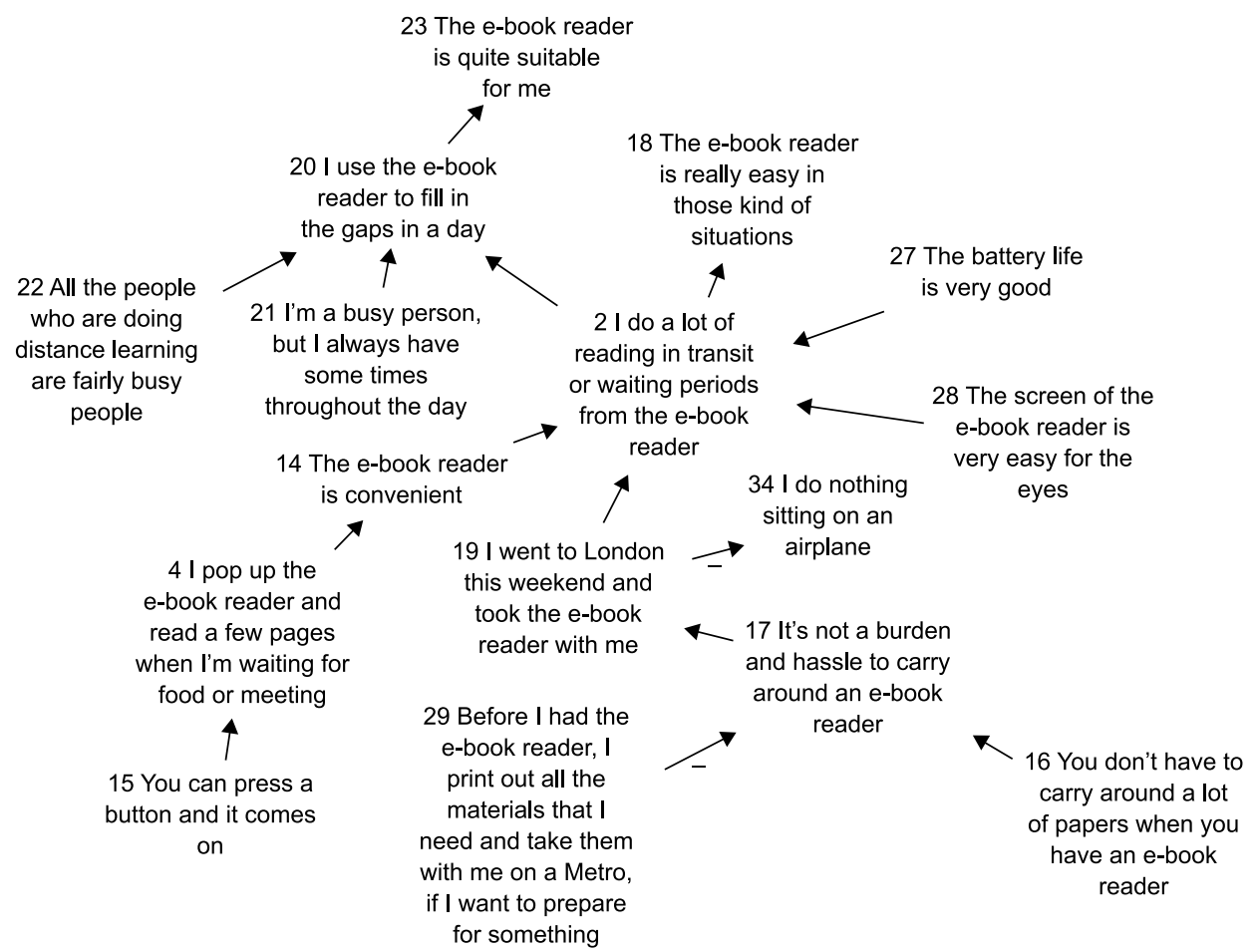

Figure 3. Effective use of time.

Table 5. Has the e-book reader changed students' study?

\begin{tabular}{lccc}
\hline $\begin{array}{l}\text { Has the e-book reader } \\
\text { changed the way you study? }\end{array}$ & $\begin{array}{c}\text { Education } \\
\text { students }\end{array}$ & OP students & Total \\
\hline Yes & 8 & 3 & 11 \\
No & 9 & 8 & 17 \\
\hline
\end{tabular}

Interviews with students revealed further detail on what changed as a result of having an e-book reader. An interview with an Education student showed that the e-book reader enabled her to change strategies for keeping notes:

The e-book reader changed my way of keeping notes and made my study more effective. Before, I used my laptop to write a lot of notes because I feel I will forget the whole thing if I don't take them down. But taking notes is time-consuming and not that effective because I never really use the notes. With the e-book reader, it's not very inconvenient to go back to the material on the e-reader, and I can remember where the material was and go back to the module on the e-reader and look through it. As a result of that, I didn't take a lot of notes and I don't think that it [not taking notes] makes a difference to my study. (Edu2)

For some students, the e-book reader was not a substitute for other forms or means of reading. It offered them a choice about what to use in a given situation. A causal 
map developed from an interview with an Education student (Figure 4) illustrates how he chose different devices for reading to suit his situations and needs.

Figure 4 shows reading habits that are highly situational. This student uses his laptop and books for conducting research because he considers cross-referencing speedy and intuitive (Concept 31). He still prints out materials when he wants to make notes (Concepts 9 and 11). He does not use his e-book reader on public transport or when travelling because he finds those environments too noisy to read (Concept 20). He prefers to use his e-book reader at home when he has a quiet time (Concept 27). He chooses to use his iPhone ${ }^{\mathrm{TM}}$ for quick checks (Concept 29).

Another interview with an OP student indicated that the e-book reader enabled her to change strategies for reading and approaches to assignments:

The e-book reader has changed my approach to how I do assignments to some extent. Previously, I started my assignments after I'd done all the readings from print. I now start from the assignment and then read the material. I'm being more selective now in what I'm reading, and it's saving me time in a way. Before I just tried to read everything, I worked a lot harder before but I didn't really get the grades. (Psy1)

On the one hand, the e-book reader enabled this student to become more selective in reading, resulting in saving time and being more effective in approaching assignments. On the other hand, this student is reading less and becoming more strategic in her study. The case of this student suggests that the increased access and convenience afforded by the e-book reader resulted in less reading but better grades. Questions regarding breadth and depth of reading and the role of technology to promote better learning require further examination.

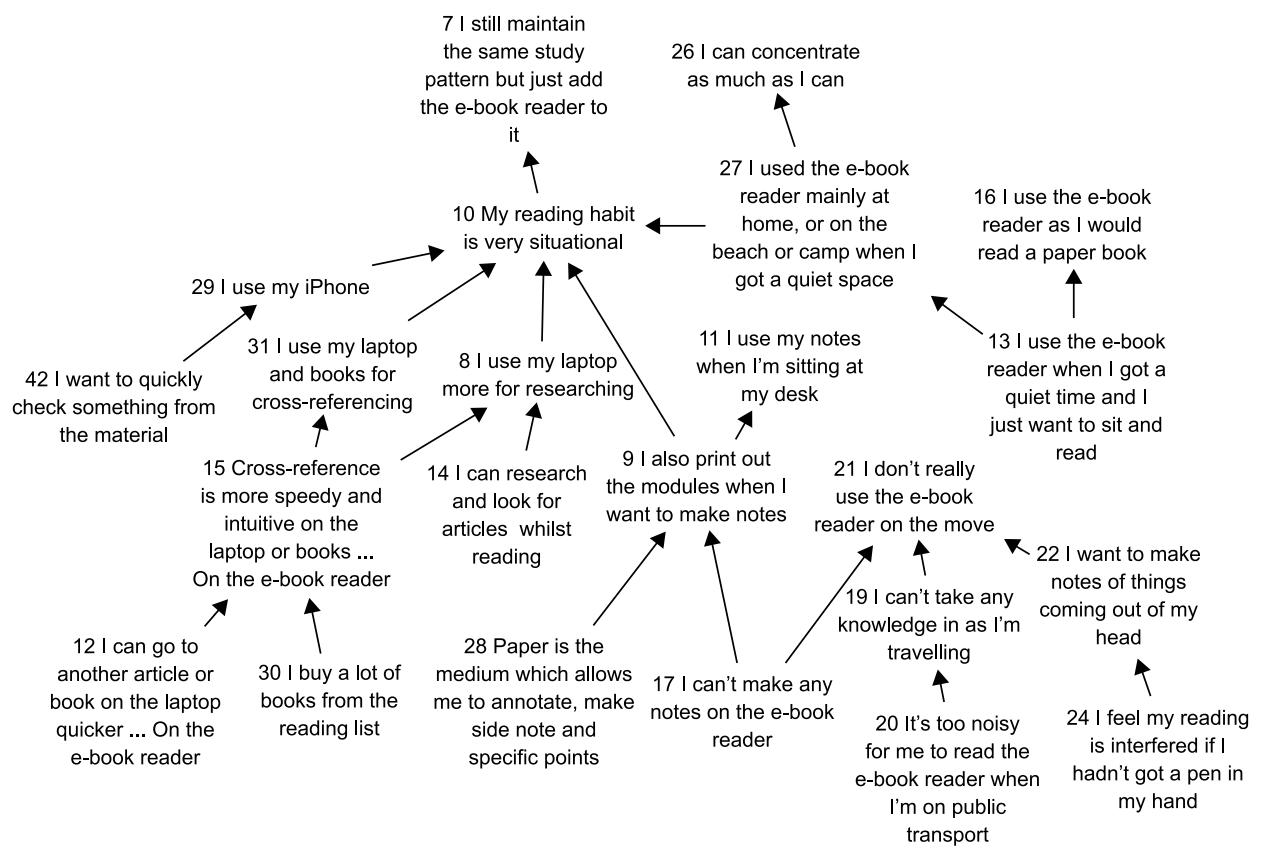

Figure 4. Situational reading. 


\section{Cost-effectiveness}

Some students became less dependent on printed materials or more selective in what they printed out as a result of having access to course materials on their e-book readers:

... reading off the internet causes me eye strain. Thus I would prefer to print off any reading to reading it online. However, reading from an e-book reader causes no strain and provides me with an equivalent reading experience, thus removing the necessity of print in my case. (Edu12)

I do like to have paper copies some of the time, but not all the time. I can read the notes on the e-book reader. If I think I need a copy I will print them out. If the memory was bigger I probably wouldn't print out that much at all. (Psy1)

The causal maps reinforced this finding. For example, an Education student explained how he was able to save Can $\$ 100$ from printing materials (Figure 5), which suggests that delivering course materials on e-book readers can offer cost-saving benefits to students.

Cost-cutting was not the motivation behind the introduction of e-book readers by either course team. Instead, the move was part of a pedagogical innovation process designed to help enrich the students' learning experience with interactive, flexible and portable course materials. Table 6 summarises the costs involved in the incorporation of e-book readers into these teaching programmes in 2009.

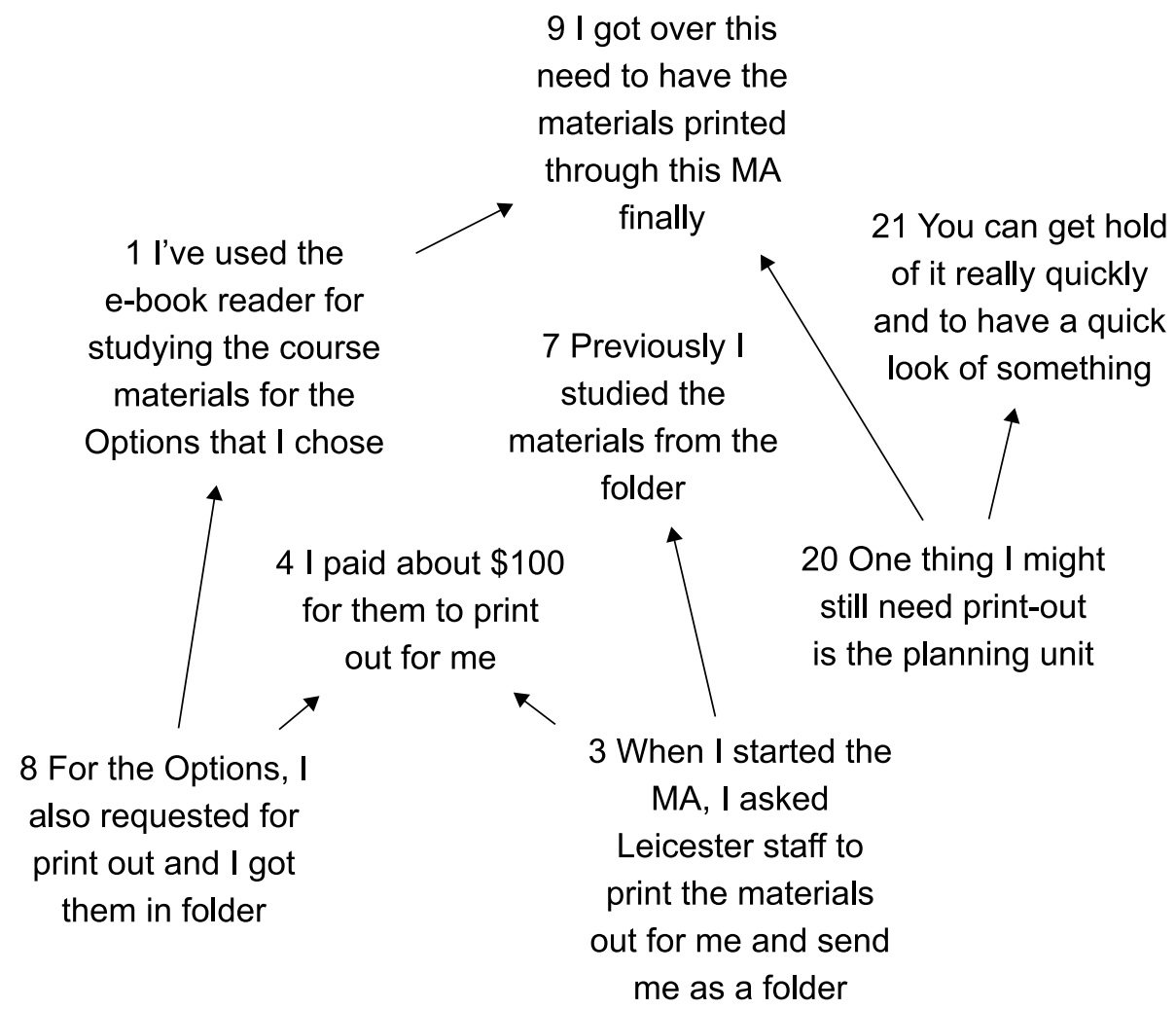

Figure 5. Cost saving for students. 
Table 6. Cost of introducing e-book readers in 2009.

\begin{tabular}{lll}
\hline Cost category & Item & Costs per student \\
\hline Device & $\begin{array}{c}\text { SONY-PRS-505TM (discontinued), } \\
\text { replaced by SONY PRS-300 }\end{array}$ & $£ 150$ \\
Delivery & Secure DHL delivery & $£ 30$ per parcel overseas \\
Materials & $\begin{array}{c}\text { Formatting and converting module } \\
\text { materials into ePub }\end{array}$ & Averaged at $£ 60$ per device \\
Total cost per student & & $£ 240$ \\
\hline
\end{tabular}

\section{Limitations in functionality}

Generally, students were unimpressed by the lack of a note-taking feature in the Sony PRS-505'TM. This drawback limited student use of the device. Evidence showed that the e-book reader was considered appropriate for light reading, such as reading for a general overview. Students went back to the printed materials, where they could underline and make notes, especially during revision and preparation for assignments or the dissertation. Some considered e-book readers more useful and appropriate for reading for leisure than for study purposes.

The e-book readers used in this study offered users one major benefit: a pleasant and efficient reading experience, providing some motivation for them to keep up the effort of studying alongside their busy work and home lives. Higher-specification models, including the Sony PRS- $600^{\mathrm{TM}}$ and other devices such as the Amazon Kindle $^{\mathrm{TM}}$ and Apple's iPad ${ }^{\mathrm{TM}}$, offer highlighting and annotation functions. Further research is needed to establish the extent to which this note-taking feature is usable and practical enough to change study habits and enable a better learning experience.

Another functionality that students were not satisfied with was the delay in pageturning, which causes 'blinking' or 'flickering'. This adds about one or two seconds to page-turning, which some found "disappointing", sometimes "disturbing" and "annoying". However, evidence showed that the majority of the students put up with this discomfort and continued to use their e-book readers on a regular basis. Only one student stated that she completely gave up on the device because of this limitation.

Students identified further areas for improvement and came up with the following wishlist: a bigger screen, a touchscreen, wireless connectivity, better presentation of tables and diagrams, and a more intuitive, straight-forward solution for converting Word documents into ePub format. Newer devices, such as the third-generation Kindle $^{\mathrm{TM}}$ and the $\mathrm{iPad}{ }^{\mathrm{TM}}$ do offer some of these benefits. The former is cheaper than the Sony models we used in 2009 and offers a range of additional benefits, including a keyboard, Wi-Fi and optional $3 \mathrm{G}$ connectivity.

\section{Discussion}

The evidence points to a range of advantages that an e-book reader can offer to workbased distance learners. These benefits suggest that the device can effectively address the initial challenges faced by the course teams on the DUCKLING project: flexibility in curriculum delivery to accommodate the needs and demands of highly mobile learners, and maximising the benefit of limited and fragmented study time. The findings point to additional benefits of the e-book reader to work-based learners. Table 7 summarises these points. 
Table 7. Summary of key advantages of e-book readers in curriculum delivery.

\begin{tabular}{lc}
\hline Finding & Key points \\
\hline $\begin{array}{l}\text { Enhanced flexibility in } \\
\text { curriculum delivery to } \\
\text { meet mobility demands }\end{array}$ & $\begin{array}{c}\text { Students used their e-book readers in different places (at home, } \\
\text { in the office, in public places and on the move) to access all } \\
\text { Better use of time }\end{array}$ \\
$\begin{array}{c}\text { essential course readings. } \\
\text { Students found it easy to take the e-book reader anywhere and } \\
\text { read whenever an opportunity arises. They filled in the gaps } \\
\text { during the day for study purposes. } \\
\text { New study strategies }\end{array}$ & $\begin{array}{c}\text { Some students changed their strategies for reading, keeping } \\
\text { notes and approaching assignments. Some students opted } \\
\text { for the e-book reader for reading while on the move, the } \\
\text { iPhone } \\
\text { taking for a quick check, and printed material for note- } \\
\text { As a direct result of the availability of the e-book reader, some } \\
\text { students were less dependent on printed material and more } \\
\text { selective when printing materials out. }\end{array}$ \\
&
\end{tabular}

\section{Access to other readings}

In addition to using the pre-loaded materials, 18 out of 28 students transferred journal articles and eight copied other Internet materials onto the device for study purposes. Thirteen transferred novels to their e-book readers for leisure purposes (Table 8). This suggests that the device enabled students to read beyond the immediate requirements and materials of the course.

\section{Technical experience and skills}

The evidence suggests that the e-book reader does not place high demands on the learner in terms of technical skills. Twenty-one students from both disciplines found the e-book readers easy to use for reading course materials (Table 9). Twenty-two students from both disciplines found the process of transferring additional materials to the e-book readers straight-forward (Table 10).

\section{Copyright and intellectual property rights}

Intellectual property rights and copyright are major issues encountered in this study. Despite extensive help and collaboration from the university's library and contacts

Table 8 . Content added by learners to their e-book readers.

\begin{tabular}{lccc}
\hline Type of content & Education students & OP students & Total \\
\hline Course-related material (i.e. journal articles) & 11 & 7 & 18 \\
Novels & 9 & 4 & 13 \\
Support material from other sources (i.e. the & 6 & 2 & 8 \\
$\quad$ Internet) & 4 & 0 & 4 \\
Documents created by the student him/herself & 1 & 1 & 2 \\
Images & & & \\
\hline
\end{tabular}


Table 9. To what extent do students find the e-book reader easy to use for reading materials?

To what extent do you find the e-book reader easy to use for reading?

\begin{tabular}{ccc} 
Education students & OP students & Total \\
\hline 5 & 4 & 9 \\
7 & 5 & 12 \\
4 & 2 & 6 \\
1 & 0 & 1 \\
0 & 0 & 0 \\
\hline
\end{tabular}

made at all levels, publishers gave blanket refusals to pre-loading copyrighted materials such as e-books and journal articles onto the e-book readers. A single Education e-book on socio-linguistics was made available on the e-book readers after obtaining agreement from its publisher. The e-book readers could have been much more useful if all essential readings, including core textbooks and journal articles, had been preloaded on them.

To sustain and scale up the use of the device, a possible way forward is the extensive use of open educational resources. Further research is needed to establish the feasibility and impact of this approach in conjunction with e-book readers.

\section{Conclusions}

This research has illustrated an innovation in the delivery of work-based distance learning programmes through the incorporation of e-book readers. The evidence showed that the students welcomed the innovation. The device enhanced the student learning experience by increasing flexibility in curriculum delivery to meet their mobile lifestyles, enabling relatively cheap and rapid access to essential readings, filling 'dead' time slots with useful reading and promoting changes to study strategies. It also reduced costs for some students, who became more selective in what they chose to print out. In summary, this innovation has increased the perceived quality of distance learning for students who value flexibility and learning on the move. With appropriate design and planning, the e-book reader made the work-based distance learner's life easier.

Limitations in functionality, which have, at least to some extent, been overcome in later models, constituted a hurdle for some students. Intellectual property rights and copyright restrictions have limited our ability to make other essential readings available

Table 10. How easy it is to transfer documents onto the e-book reader?

\begin{tabular}{lccr}
\hline $\begin{array}{l}\text { How easy it is to transfer documents } \\
\text { onto the e-book reader? }\end{array}$ & Education students & OP students & Total \\
\hline Very easy & 3 & 1 & 4 \\
Relatively easy & 11 & 7 & 18 \\
Relatively difficult & 0 & 1 & 1 \\
Very difficult & 1 & 0 & 1 \\
I've never transferred any & 2 & 2 & 4 \\
documents onto my e-book reader & & & \\
\hline
\end{tabular}


on the device, such as prescribed e-books and journal articles. To enable the benefits of e-book readers in distance education to be enjoyed on a wider scale, a possible way forward is to encourage students who have their own mobile reading devices (e.g. smartphones, netbooks, Kindles ${ }^{\mathrm{TM}}$ ) to use these devices for study purposes, and to provide support by making course materials available in ePub format, and linking to guidelines on downloading library resources to mobile devices.

Students with mobile reading devices could also be encouraged to explore relevant open educational resources, as a way of increasing access to quality material and keeping costs low. Further research is needed to establish the feasibility and impact of these approaches to the use of e-book readers.

\section{Further research}

Several areas have emerged as suitable for further investigation. e-Book readers have changed rapidly over the past two years and are very much in transition. More recent e-book reader models than the ones used in this research are not only cheaper and faster, but they offer a range of functions that our students would have benefited from, such as highlighting text, annotation, Wi-Fi and $3 \mathrm{G}$ connectivity. Whether these additional features would contribute to better reading and learning experiences is worth researching.

Many advocates of e-books and e-book readers use the 'green' argument to make their case. This certainly merits proper research. At present, it is unclear whether the amounts of metal (including lithium), glass, rubber and other components involved in building and disposing of e-book readers make the device any 'greener' than printed books. How many paper books do we need to read for an e-book reader to become a 'greener' alternative?

Better access to course materials and new study strategies does not necessarily mean better reading comprehension or better learning. The case has also been made (Richtel 2010) that we deprive our brains of much-needed 'downtime' by using every spare moment to read, where previously we might have used the opportunity to daydream or reflect.

Finally, it would be of interest to see how distance education providers respond to this type of technology in terms of the development of learning materials, technological infrastructure and cost models for their programmes. All these questions merit further investigation.

\section{Acknowledgements}

Figure 1 was created by Emma Davies and Terese Bird, University of Leicester.

\section{References}

Andresen, L., D. Boud, and R. Cohen. 1999. Experience-based learning. In Understanding adult education and training, ed. G. Foley, 225-39. 2nd ed. Sydney: Allen \& Unwin.

Boyatzis, R.E. 1998. Transforming qualitative information: Thematic analysis and code development. London: Sage.

Brennan, L. 2005. Integrating work-based learning into higher education - A guide to good practice. Bolton: University Vocational Awards Council. http://www.uvac.ac.uk/ 0402.html.

Bryson, J.M., F. Ackermann, C. Eden, and C.B. Finn. 2004. Visible thinking: Unlocking causal mapping for practical business results. Chichester: John Wiley \& Sons. 
Clamp, E., and E. Warr. 2002. Addressing employability through implementation of workrelated learning. Paper presented at Skills Development in Higher Education: Forging Links, July 10-11, at the University of Hertfordshire, Hatfield, UK.

Curseu, P., R. Schalk, and S. Schruijer. 2010. The use of cognitive mapping in eliciting and evaluating group cognitions. Journal of Applied Social Psychology 40, no. 5: 1258-91.

Fagerberg, T. and T. Rekkedal. 2004. Enhancing the flexibility of distance education Designing and trying out a learning environment for mobile distance learners. Paper presented at the 21 st ICDE World Conference on Open Learning \& Distance Education, February 18-21, in Hong Kong.

Gallacher, J., and F. Reeve. 2002. Work-based learning: The implications for higher education and for supporting informal learning in the workplace. Milton Keynes: Open University. http://www.open.ac.uk/lifelong-learning/papers/index.html.

Gray, D. 2001. A briefing on work-based learning. Learning and Teaching Support Network Generic Centre, Assessment Series No. 11. York: LTSN. http://www.bioscience.heacademy.ac.uk/ftp/Resources/gc/assess11Workbased.pdf.

Harris, E., and R. Woolley. 2009. Facilitating innovation through cognitive mapping of uncertainty. International Studies of Management \& Organisation 39, no. 1: 70-100.

Hills, J.M., G. Robertson, R. Walker, M. Adey, and I. Nixon. 2003. Bridging the gap between degree curricula and employability through implementation of work-related learning. Teaching in Higher Education 8, no. 2: 211-23.

Joffe, H., and L. Yardley. 2004. Content and thematic analysis. In Research methods for clinical and health psychology, ed. D.F. Marks and L. Yardley, 56-68. London: Sage.

Kelly, G. 1955. The psychology of personal constructs. New York: Norton.

Lam, P., J. Lam, and C. McNaught. 2010. How usable are eBooks in an mLearning environment? International Journal of Continuing Engineering Education and Life Long Learning 20, no. 1: 6-20.

McGreal, P., B. Cheung, T. Tin, and S. Schafer. 2005. The Athabasca University Digital Reading Room: Library resources for mobile students. Proceedings of IADIS International Conference on Mobile Learning 2005, June 28-30, in Qawra, Malta, 47-54. Lisbon: IADIS.

McNiff, J., and J. Whitehead. 2006. All you need to know about action research. London: Sage.

Nie, M., A. Armellini, S. Harrington, K. Barklamb, and R. Randall. 2010. The role of podcasting in effective curriculum renewal. ALT-J, Research in Learning Technology 18, no. 2: $105-18$.

Nixon, I., K. Smith, R. Stafford, and S. Camm. 2006. Work-based learning: Illuminating the higher education landscape. York: Higher Education Academy. http://www.heacademy.ac.uk/assets/York/documents/ourwork/research/wbl_illuminating.pdf.

Rekkedal, T., A. Dye, T. Fagerberg, S. Bredal, B. Midtsveen, and J. Russell. 2005. Design, development and evaluation of mobile learning at NKI distance education 2000-2005. Norway: NKI Forlaget. http://www.dye.no/articles/mlearning/m_Learning_2000_2005.pdf.

Richtel, M. 2010. Digital devices deprive brain of needed downtime. The New York Times, August 24, Technology section. http://www.nytimes.com/2010/08/25/technology/ 25brain.html?pagewanted=1\&_r=1.

Russell, C. 2009. A systemic framework for managing e-learning adoption in campus universities: Individual strategies in context. ALT-J, Research in Learning Technology 17, no. 1: $3-19$.

Shiratuddin, N., M. Landoni, F. Gibb, and S. Hassan. 2003. E-book technology and its potential applications in Distance Education. Journal of Digital Information 3, no. 4. http:// journals.tdl.org/jodi/article/view/90/89.

van Kouwen, F., C. Dieperink, P. Schot, and M. Wassen. 2009. Computer-supported cognitive mapping for participatory problem structuring. Environment and Planning 41: 63-81.

Walton, G., S. Childs, and E. Blenkinsopp. 2005. Using mobile technologies to give health students access to learning resources in the UK community setting. Health Information and Libraries Journal 22: 51-65.

Whalley, B. 2010. Learner acceptance of on-line learning and e-learning. Association for Learning Technology. http://wiki.alt.ac.uk/index.php/Learner_acceptance_of_on-line_ learning_and_e-learning. 


\section{Appendix 1. e-Book reader survey questions}

1. Can you tell us your initial impression and thoughts about the e-book reader when you first received it and started to use it?

2. Now you have been using the e-book reader for a while, have these thoughts and impressions changed at all, and in what way?

3. How often do you use the Course Module material on the e-book reader?

4. How often do you use the podcasts on the e-book reader?

5. How long do you use the e-book reader each time?

6. If you answered 'It depends' to Question 5, can you please briefly explain?

7. Where do you usually use the e-book reader?

8. To what extent do you find the Course Module material on the e-book reader easy to read?

9. To what extent do you find the podcasts on the e-book reader easy to use?

10. If you find the course materials or podcasts on the e-book reader difficult to use, can you briefly explain why?

11. How helpful do you find the e-book reader in your studies?

12. Can you briefly explain your choice in Question 11 ?

13. Has the e-book reader changed the way that you study?

14. If you answered 'Yes' to Question 13, can you briefly explain what has been changed?

15. Are there any functions that you wish the e-book had that would help in your studies?

16. Given these three choices of having the course material in print, e-book reader or the Blackboard online format, please rank your preferences for reading your course material.

17. Can you briefly justify the order you chose in Question 16 ?

18. Giving these three choices of listening to the course podcasts on iPod/iPhone/MP3 player, e-book reader or Blackboard online, please rank your preferences for using the podcasts?

19. Can you briefly justify the order your chose in Question 18 ?

20. Can you tell us what else you use the e-book reader for?

21. If you answered 'Others' to Question 20, can you please explain briefly what other activities you used the e-book reader for?

22. How easy it is to transfer documents onto the e-book reader?

23. If you find it difficult to transfer documents onto your e-book reader, can you briefly explain what the problem or difficulty is?

24. Please rate your overall satisfaction with the e-book reader.

25. If you're not satisfied with the e-book reader, can you briefly explain the reason?

25. Overall, how would you summarise your experience with the e-book reader? 